\title{
What really matters - response and resistance in cancer therapy
}

\author{
Tim R. Fenton, Michelle D. Garrett, Mark N. Wass, Martin Michaelis \\ School of Biosciences, University of Kent, Canterbury CT2 7NJ, UK.
}

Correspondence to: Dr. Tim R. Fenton, Dr. Michelle D. Garrett, Dr. Mark N. Wass, and Dr. Martin Michaelis, School of Biosciences, University of Kent, Canterbury CT2 7NJ, UK. E-mails: t.fenton@kent.ac.uk; m.d.garrett@kent.ac.uk; m.n.wass@kent.ac.uk; m.michaelis@kent.ac.uk

\begin{abstract}
How to cite this article: Fenton TR, Garrett MD, Wass MN, Michaelis M. What really matters - response and resistance in
\end{abstract} cancer therapy. Cancer Drug Resist 2018;1:200-3. http://dx.doi.org/10.20517/cdr.2018.19

Received: 12 Oct 2018 First Decision: 18 Oct 2018 Revised: 30 Oct 2018 Accepted: 30 Oct 2018 Published: 19 Dec 2018

Science Editor: Godefridus J. Peters Copy Editor: Huan-Liang Wu Production Editor: Zhong-Yu Guo

From 10th to 12th September of 2018, we held the first British Association of Cancer Research (BACR) Special Conference on "Response and Resistance in Cancer Therapy" at the University of Kent, Canterbury, UK. The conference theme is the subject of this Special Issue of Cancer Drug Resistance and we hope this editorial and the following contributions, will give you an insight into this important topic.

As we all know, cancer is a major global killer. According to Globocan (http://globocan.iarc.fr/Pages/ fact_sheets_cancer.aspx), there "were 14.1 million new cancer cases, 8.2 million cancer deaths and 32.6 million people living with cancer (within 5 years of diagnosis) in 2012 worldwide". Early diagnosis and local therapy including surgery and local radiotherapy with or without adjuvant chemotherapy have largely accounted for the progress made in curing cancer. Apart from a few exceptions (e.g., testicular cancer, Hodgkin's lymphoma, childhood acute lymphoblastic leukaemia) cure rates remain low for cancers that cannot be effectively treated by localised therapy. This is typically metastatic disease, which depends on systemic treatment. In such cases, the focus is largely placed on improving and prolonging life ${ }^{[1-7]}$.

It has often been argued that, because the outcome is particularly poor in metastatic disease, pathways driving metastasis constitute prime therapeutic targets ${ }^{[8-10]}$. Although it is undoubtedly true that the presence of metastases is the number one determinant of poor outcomes in most types of cancer, the efficacy of therapeutic targets in this area is much less clear. The vast majority of cancers with poor prognosis already present with unresectable, typically metastatic disease at diagnosis, even if the metastases cannot be detected at that point ${ }^{[1,2,4,5]}$. In this scenario, inhibition of further metastasis formation may prolong life but its curative potential is limited.

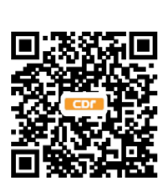


Unsatisfactory outcomes of systemic anti-cancer therapies in advanced, metastatic disease have also fuelled calls for better strategies for early diagnosis that detect cancer when it is still at a localised, manageable stage. However, biomarkers for the timely detection of most cancer types are currently still lacking ${ }^{[11-14]}$. Even if reliable biomarkers become available, early recognition may not always improve treatment outcome. For example, a mass screening programme for the early detection of neuroblastoma in children using vanillylmandelic acid as a biomarker was performed in Japan from 1985 to 2003 . However, the programme was stopped because it resulted in an increased incidence of neuroblastoma but not in reduced mortality, indicating over diagnosis of cases that did not require therapy ${ }^{[15,16]}$. The benefit of mammography-based screening programmes for breast cancer is also currently under dispute. Studies suggest that for every woman whose life is prolonged through breast cancer screening, ten women receive unnecessary treatment. Many women lose subjectively healthy lifetime, because treatment outcome is the same as if therapy had started upon the onset of symptoms. False positive results cause anxiety to affected women. Finally, overdetection, -diagnosis and -treatment of patients who would never have developed a clinically relevant disease is an issue ${ }^{[14,17-20]}$.

Of course, we do not dispute the value of understanding metastasis formation, or, of early detection in cancer. We simply emphasise that for the foreseeable future, there will be patients who are diagnosed with advanced disease that requires systemic therapy. Hence, there is an ongoing need to develop better therapies for such patients. The main obstacle to this is resistance. Improved strategies are urgently required for those cancers that either fail to respond altogether to treatment ("intrinsic" or "upfront" resistance), or stop responding during treatment ("acquired" resistance).

Resistance to anti-cancer therapies is largely a consequence of the small therapeutic window often demonstrated by these treatments. The aim of every cancer therapy is to kill all cancer cells or at least to permanently stop their proliferation. In contrast to therapies designed to fight single cell pathogens (bacteria, fungi, parasites) or viruses, cancer cells are derived from host cells and do not offer specific ("foreign") targets in the same way. Instead they differ in the expression level of genes and the activation status of pathways that are also present in normal cells. Hence, therapeutic drug concentrations are commonly associated with adverse events. Cytotoxic anti-cancer therapies typically interfere with basic cellular processes by inducing DNA damage or targeting the process of cell division. They are generally applied at the "maximum tolerated dose", which makes further dosage increase impossible. Hence, even the formation of low-level resistance results in therapy failure ${ }^{[21-28]}$.

Some protein kinase inhibitors (e.g., first-generation epidermal growth factor receptor and BCR-ABL inhibitors) and antibodies interfere more specifically with cancer abnormalities and are characterised by better tolerability. However, resistance formation may be an even bigger issue as cures are rare and resistance formation often inevitable $e^{[26,27,29-35]}$. This may be because it is easier for cancer cells to bypass their more selective impact, analogous to the rapid development of resistance to highly specific antiviral therapies; a well-known and recognised phenomenon ${ }^{[36-39]}$.

Immunotherapies, in particular immune checkpoint inhibitors including cytotoxic T lymphocyte associate protein-4, programmed cell death 1 ( $\mathrm{PD}-1)$, and $\mathrm{PD}$-ligand 1, inhibitors have shown great promise for subgroups of patients suffering from specific forms of cancer including melanoma, renal-cell carcinoma, non-small-cell lung cancer, and head and neck cancer. Although these therapies are transformative for some patients, many do not benefit and long-term responses only occur in a minority of patients. The mechanisms underlying these differences are poorly understood, and biomarkers that would predict therapy response are lacking. In addition, immune checkpoint inhibitor-based therapies are also associated with severe adverse events. Hence, toxicity and resistance are also important issues during the development and improvement of such therapies ${ }^{[40-42]}$. 
In conclusion, a lack of response or resistance to anti-cancer therapies, whichever you prefer to call it, is the key obstacle that needs to be overcome to improve therapy outcomes in patients diagnosed with advanced disease who depend on systemic therapies. You will see from the conference abstracts and the contributions to this Special Issue that a wide spectrum of aspects of response and resistance in cancer were covered at the conference. We would like to thank all the contributors to this Special Issue and hope that you, the reader, will find the topic and content both interesting and useful. Finally, we encourage you to join us at the follow-up 2nd BACR Conference on Response and Resistance in Cancer Therapy, which is planned for 15th to 17th June 2020 at the University of Kent in Canterbury, UK.

\section{DECLARATIONS}

\section{Authors' contributions}

All authors contributed to the writing and revision of the article and read and approved the final version.

\section{Availability of data and materials}

Not applicable.

\section{Financial support and sponsorship}

None.

\section{Conflicts of interest}

All authors declared that there are no conflicts of interest.

\section{Ethical approval and consent to participate}

Not applicable.

\section{Consent for publication}

Not applicable.

\section{Copyright}

(c) The Author(s) 2018.

\section{REFERENCES}

1. Kamat AM, Hahn NM, Efstathiou JA, Lerner SP, Malmström PU, et al. Bladder cancer. Lancet 2016;388:2796-810.

2. Harbeck N, Gnant M. Breast cancer. Lancet 2017;389:1134-50.

3. Iacobucci I, Mullighan CG. Genetic basis of acute lymphoblastic leukemia. J Clin Oncol 2017;35:975-83.

4. Litwin MS, Tan HJ. The diagnosis and treatment of prostate cancer: a review. JAMA 2017;317:2532-42.

5. Herbst RS, Morgensztern D, Boshoff C. The biology and management of non-small cell lung cancer. Nature 2018;553:446-54.

6. Lim SH, Johnson PWM. Optimizing therapy in advanced-stage Hodgkin lymphoma. Blood 2018;131:1679-88.

7. Pierorazio PM, Albers P, Black PC, Tandstad T, Heidenreich A, et al. Non-risk-adapted surveillance for stage I testicular cancer: critical review and summary. Eur Urol 2018;73:899-907.

8. Steeg PS. Targeting metastasis. Nat Rev Cancer 2016;16:201-18.

9. Paul CD, Mistriotis P, Konstantopoulos K. Cancer cell motility: lessons from migration in confined spaces. Nat Rev Cancer 2017; $17: 131-40$

10. Hamidi H, Ivaska J. Every step of the way: integrins in cancer progression and metastasis. Nat Rev Cancer 2018;18:533-48.

11. Sopik V, Rosen B, Giannakeas V, Narod SA. Why have ovarian cancer mortality rates declined? Part III. Prospects for the future. Gynecol Oncol 2015;138:757-61.

12. Erben V, Bhardwaj M, Schrotz-King P, Brenner H. Metabolomics biomarkers for detection of colorectal neoplasms: a systematic review. Cancers (Basel) 2018;10:E246.

13. Li J, Han X, Yu X, Xu Z, Yang G, et al. Clinical applications of liquid biopsy as prognostic and predictive biomarkers in hepatocellular carcinoma: circulating tumor cells and circulating tumor DNA. J Exp Clin Cancer Res 2018;37:213.

14. Loke SY, Lee ASG. The future of blood-based biomarkers for the early detection of breast cancer. Eur J Cancer 2018;92:54-68. 
15. Sawada T, Hirayama M, Nakata T, Takeda T, Takasugi N, et al. Mass screening for neuroblastoma in infants in Japan. Interim report of a mass screening study group. Lancet 1984;324:271-3.

16. Shinagawa T, Kitamura T, Katanoda K, Matsuda T, Ito Y, et al. The incidence and mortality rates of neuroblastoma cases before and after the cessation of the mass screening program in Japan: a descriptive study. Int J Cancer 2017;140:618-25.

17. Gøtzsche PC, Jørgensen KJ. Screening for breast cancer with mammography. Cochrane Database Syst Rev 2013:CD001877.

18. Bleyer A. Screening mammography: update and review of publications since our report in the New England Journal of Medicine on the magnitude of the problem in the United States. Acad Radiol 2015;22:949-60.

19. Ripping TM, Ten Haaf K, Verbeek ALM, van Ravesteyn NT, Broeders MJM. Quantifying overdiagnosis in cancer screening: a systematic review to evaluate the methodology. J Natl Cancer Inst 2017;109: doi: 10.1093/jnci/djx060.

20. Wallis MG. How do we manage overdiagnosis/overtreatment in breast screening? Clin Radiol 2018;73:372-80.

21. DeVita VT Jr, Chu E. A history of cancer chemotherapy. Cancer Res 2008;68:8643-53.

22. Zaffiri L, Gardner J, Toledo-Pereyra LH. History of antibiotics. From salvarsan to cephalosporins. J Invest Surg 2012;25:67-77.

23. Holohan C, Van Schaeybroeck S, Longley DB, Johnston PG. Cancer drug resistance: an evolving paradigm. Nat Rev Cancer 2013;13:714-26.

24. Zaffiri L, Gardner J, Toledo-Pereyra LH. History of antibiotics: from fluoroquinolones to daptomycin (Part 2). J Invest Surg 2013;26:167-79.

25. De Clercq E, Li G. Approved antiviral drugs over the past 50 years. Clin Microbiol Rev 2016;29:695-747.

26. Sachs JR, Mayawala K, Gadamsetty S, Kang SP, de Alwis DP. Optimal dosing for targeted therapies in oncology: drug development cases leading by example. Clin Cancer Res 2016;22:1318-24.

27. Wong KM, Capasso A, Eckhardt SG. The changing landscape of phase I trials in oncology. Nat Rev Clin Oncol 2016;13:106-17.

28. McCarthy MW, Kontoyiannis DP, Cornely OA, Perfect JR, Walsh TJ. Novel agents and drug targets to meet the challenges of resistant fungi. J Infect Dis 2017;216:S474-83.

29. Gatzka MV. Targeted tumor therapy remixed-an update on the use of small-molecule drugs in combination therapies. Cancers (Basel) 2018; 10:E155.

30. Kavanagh S, Nee A, Lipton JH. Emerging alternatives to tyrosine kinase inhibitors for treating chronic myeloid leukemia. Expert Opin Emerg Drugs 2018;23:51-62.

31. Kleczko EK, Heasley LE. Mechanisms of rapid cancer cell reprogramming initiated by targeted receptor tyrosine kinase inhibitors and inherent therapeutic vulnerabilities. Mol Cancer 2018;17:60.

32. Larionov AA. Current therapies for human epidermal growth factor receptor 2-positive metastatic breast cancer patients. Front Oncol 2018;8:89.

33. Sharma GG, Mota I, Mologni L, Patrucco E, Gambacorti-Passerini C, et al. Tumor resistance against ALK targeted therapy-where it comes from and where it goes. Cancers (Basel) 2018;10:E62.

34. Soverini S, Mancini M, Bavaro L, Cavo M, Martinelli G. Chronic myeloid leukemia: the paradigm of targeting oncogenic tyrosine kinase signaling and counteracting resistance for successful cancer therapy. Mol Cancer 2018;17:49.

35. Tomasello C, Baldessari C, Napolitano M, Orsi G, Grizzi G, et al. Resistance to EGFR inhibitors in non-small cell lung cancer: clinical management and future perspectives. Crit Rev Oncol Hematol 2018;123:149-61.

36. Bock C, Lengauer T. Managing drug resistance in cancer: lessons from HIV therapy. Nat Rev Cancer 2012;12:494-501.

37. Garbelli A, Riva V, Crespan E, Maga G. How to win the HIV-1 drug resistance hurdle race: running faster or jumping higher? Biochem J 2017;474:1559-77.

38. Britt WJ, Prichard MN. New therapies for human cytomegalovirus infections. Antiviral Res 2018;159:153-74.

39. Hamers RL, Rinke de Wit TF, Holmes CB. HIV drug resistance in low-income and middle-income countries. Lancet HIV 2018;5:e588-96

40. Anderson R, Rapoport BL. Immune dysregulation in cancer patients undergoing immune checkpoint inhibitor treatment and potential predictive strategies for future clinical practice. Front Oncol 2018;8:80.

41. Davis MP, Panikkar R. Checkpoint inhibitors, palliative care, or hospice. Curr Oncol Rep 2018;20:2.

42. Li X, Shao C, Shi Y, Han W. Lessons learned from the blockade of immune checkpoints in cancer immunotherapy. J Hematol Oncol 2018;11:31. 